\title{
VISITA VIRTUAL AO MUSEU: UMA PROPOSTA TURÍSTICA DIGITAL
}

\author{
Fernando Augusto Silva Lopes
}

\begin{abstract}
RESUMO
O presente artigo é resultado de uma pesquisa empírica desenvolvida no programa de Mestrado em Estudos Culturais da Universidade FUMEC, o qual abordou a visita virtual ao museu Inhotim como uma proposta de mediação entre tecnologia e o turismo, através da experiência conjugal de uma visita virtual versus a experiência presencial. $\mathrm{O}$ arcabouço teórico apresentado busca a representação de elementos culturais através da tecnologia digital-imagética das telas, projetando através das imbricações entre cultura e tecnologia uma reflexão sobre a experiência de visitar um ambiente através de construções algorítmicas. Por fim, o artigo discute a validade cultural desta experiência, lançando especial olhar para as construções culturais da contemporaneidade tecnológica que se materializam através das informações digitalizadas e matematicamente (pré) concebidas.
\end{abstract}

\author{
PaLAVRAS-Chave
}

Cultura; tecnologia, turismo digital; visita virtual

\section{VIRTUAL VISIT TO THE MUSEUM: A DIGITAL TOURISTIC PROPOSAL}

\begin{abstract}
This article is the result of an empirical research developed in the Master's Program in Cultural Studies of FUMEC University, which addresses the virtual visit to the Inhotim museum as a proposal of mediation between technology and tourism through the marital experience of a virtual visit versus face-to-face experience. The theoretical framework presented seeks the representation of cultural elements through the digital-imaging technology of the screens, projecting through the imbrications between culture and technology a reflection on the experience of visiting an environment through algorithmic constructions. Finally, the article discusses the cultural validity of this experience, with a special look at the cultural constructions of the technological contemporaneity that are materialized through digitalized and mathematically (pre)-conceived information.
\end{abstract}

\section{KEYWORDS}

Culture; digital tourism; technology; virtual visit 


\section{INTRODUÇÃO}

Este artigo é resultado da pesquisa de campo realizada no programa de mestrado em Estudos Culturais Contemporâneos, onde se utilizou do método da pesquisa-ação, por estar situado na esfera das práticas sociais que destacam a práxis e a construção do discurso crítico. Esta prática, embora um pouco esquecida no meio acadêmico, se tornou estruturalmente fundamental para a realização da pesquisa. A inserção do pesquisador no meio pesquisado permitiu a construção de uma análise baseada na busca dos sentidos representativos. O elemento estrangeiro inserido nesta metodologia foi a variável digital, que desloca o papel do pesquisador, uma vez que uma parcela da pesquisa se deu através da mediação das telas, situação que, substancialmente, conota dar as costas ao pesquisador. Esse deslocamento demandou uma reflexão mais profunda sobre a variável tecnológica.

Conceituar um museu no âmago deste artigo requer inicialmente ressignificar estes templos de sacralidade e fruição artística. Assim como todas as esferas do conhecimento e da vida social, os museus, desde os mais tradicionais, sofreram os impactos da informatização. O Google Arts and Culture, ao digitalizar os acervos dos principais museus em escala global, provocou uma revolução silenciosa: os museus e suas produções estão ao alcance dos dedos de qualquer usuário do planeta. Como um passe de mágica, pode-se saltar do acervo de Amílcar de Castro para uma exposição de Caravaggio. Com um simples comando, pode-se saltar de uma sala do Jüdisches Museum para o Museu do Chiado (Arantes, 2008, p. 69).

Ainda que uma grande parte da literatura considere o museu como um espaço de fruição e dotado de uma sacralidade para com as artes, uma breve navegação através do Google Arts and Culture, demonstra que a sacralidade destes templos de fruição está em xeque (Ascott, 1997, p. 159)

Santaella e Arantes (2008, p. 20) apresentam uma definição de museu, oriunda da sua vivência em museus tecnológicos (Projeto Oi Futuro) que revela uma interessante fecundidade:

museu: laboratório de experiências a partir de interações com objetos e onde podemos refletir sobre sua dimensão social, sobre as relações sobre a materialidade das coisas e as experiências que elas possibilitaram nos tempos passados e presentes, os museus oferecem uma oportunidade de refletir sobre os objetos e seu papel privilegiado na sociedade, nos permitem repensá-los e percebê-los e a nós mesmos de maneira renovada. (Santaella, 2012, p. 20)

Este conceito de museu como um espaço aberto à experimentação e às novas possibilidades de fruição, cadenciando as experiências culturais às tecnologias que possibilitam uma nova forma de viver, contemplar e engajar com os objetos expostos, representa uma definição de museu em sua vertente virtual.

Ao interagir com um museu através do Google Arts and Culture, é necessário se despir de toda a sacralidade que determina a concepção ocidental de museu. É necessário 
ainda vislumbrar uma nova forma de fruição, onde a interação entre a tela e o público cria formas diferentes, mas não descartáveis de experimentar e vivenciar os objetos à disposição em um museu virtual.

Benjamin (2012, p. 123) já apresentava, em meados do século XX, a necessidade de novas formas estéticas diante da cópia automatizada. Este conceito pode ser ressignificado diante da proposta de uma visita virtual ao museu, sendo necessário pensar em uma estética digital. Somente através de uma estética digital, será possível conceber a fruição e a aura em uma contemplação virtual. O Google apresenta sua ferramenta de virtualização como um espaço virtual, onde é possível realizar uma fruição digital. Não existe a preocupação com a representação simulada, mas fica clara a proposta de redefinir as formas como a fruição ocorre em uma dinâmica virtual. A percepção de que é possível uma estética digital abre as portas para que seja concebida uma aura digital (Jameson, 2001, p. 73).

O museu, tal qual apresentado pelo Google, é um desdobramento lógico de uma sociedade em rede, sendo que, para a realidade artística latino-americana, as possibilidades de se construir projetos aglutinantes e reeducadores, partindo do Google Arts and Culture, são infinitas e ainda pouco exploradas. A própria possibilidade de usar esta ferramenta como instrumento de criação de renda e divulgação midiática ainda se encontra em estágio larval (especialmente nos museus brasileiros). Não é mais possível pensar que a digitalização dos museus seja uma tentativa midiática de exploração simbólica. Os museus, em suas formas virtuais, são uma realidade que merece atenção (Jameson, 1997, p. 73).

Portanto, conceituar o museu dentro de uma dinâmica digital em que a própria instituição pode virtualizar-se (a ferramenta Google Arts and Culture permite a virtualização de qualquer museu, sem qualquer custo), é defini-lo como um espaço aberto às experiências, interações, hibridizações sem que haja uma relação de tempo-espaço definidos para que a contemplação e fruição possam ocorrer. É localizar o museu em um espaço que perde a sacralidade do locus em detrimento das telas. A experiência física de estar e vivenciar o museu ainda estão longe de ser suplantadas de forma plena pela experiência virtual (Leão, 1999, p. 99). Todavia, não é mais possível se definir o museu sem que se leve em consideração os impactos e ressignificações decorrentes de sua versão virtual. Esta dinâmica conceitual permite relacionar a visita virtual ao museu a uma proposta turística digital (Brandão, Alvelos \& Martins, 2012, p. 98)

\section{VISÃO OBJETIVA SOBRE A VISITA VIRTUAL AO MUSEU}

A visita virtual ao museu Inhotim ocorreu através de uma experiência empírica realizada com um grupo focal, formado por quatro homens e cinco mulheres com idades entre 24 e 61 anos, cujo objetivo seria realizar uma visita virtual aos museus MoMa, Louvre e Inhotim sendo que o museu Inhotim também foi visitado presencialmente. Após as experiências presenciais e virtuais, cada participante do grupo focal apresentou um relato discursivo sobre as experiências de visitar um museu, virtualmente e 
presencialmente. Foram apresentados os objetivos da pesquisa, sendo esclarecido para o grupo a metodologia e as formas de sistematizar a pesquisa. Após esse relato, iniciou-se a visita virtual ao museu Inhotim, que ocorreu em três etapas: a primeira, realizando uma visita livre pelo paisagismo do instituto e, posteriormente, foram visitadas três galerias pré-selecionadas, em detrimento da realização da visita presencial que ocorreria nessas mesmas galerias.

O ponto de partida para realização da visita virtual ao museu foi a ferramenta Google Arts and Culture, que utiliza técnicas do dispositivo Google Street View' para permitir que o usuário se locomova através do museu. Associadas a esta disponibilidade de locomoção, são acrescentadas as informações sobre as obras bem como a digitalização destas para que possam ser ampliadas na tela.

Sobre a apropriação cultural dessa ferramenta, é interessante notar que o Google não a vincula em sua página inicial, e tampouco não há um tutorial sobre como operá-la. O Google Arts and Culture se apresenta como uma continuidade das ferramentas do grupo, replicando as formas de navegação e controle já estabelecidas em outros dispositivos como o Street View, Earth e Maps. O Google tem utilizado essa metodologia operacional, criando um status quo de acesso que está sendo enraizado na cultura digital global, assim como os signos primitivos são transmitidos de forma automática, sem que seja necessário um aprendizado sistêmico sobre a ferramenta. A aculturação digital ficou latente na parcela do grupo focal com idade até trinta e três anos. Esses participantes, embora não conhecessem o Google Arts and Culture, conseguiram reconhecer, na visualidade gráfica da ferramenta, uma continuidade de suas atividades rotineiras na rede.

A capacidade que o Google Arts and Culture possui em reduzir as distâncias foi o primeiro fator que chamou a atenção do grupo. O primeiro contato com a ferramenta evidenciou como a tecnologia pode ser utilizada como mediadora de uma experiência cultural. Todos os membros do grupo já possuíam plena consciência do papel da tecnologia em reduzir as distâncias entre os indivíduos (telecomunicações). Todavia, a experiência cultural se mostrou como uma novidade.

A tecnologia, como mediadora da distância, como uma possibilidade de contemplar (ou acessar) um museu, foi considerada como uma grande descoberta pelo grupo. O desconhecimento de todo o grupo focal da existência e funcionamento da ferramenta Google Arts and Culture como dispositivo que permite a realização da visita ampliou a euforia em relação a esta possibilidade. Dentro desse viés do rompimento do locus do museu e do turismo pela tecnologia, a questão levantada pelo grupo foi em relação à não divulgação dessa ferramenta. O comentário de Fabiana Barbosa aborda essa questão: "como uma ferramenta que possibilita que qualquer pessoa tenha acesso aos principais museus do planeta não é divulgada, e nem sequer aparece em minha página inicial do Google?"

\footnotetext{
' Google Street View é um recurso do Google Maps e do Google Earth que disponibiliza vistas panorâmicas de $360^{\circ}$ na horizontal e $290^{\circ}$ na vertical e permite que os usuários (utilizadores) vejam partes de algumas regiões do mundo ao nível do chão/solo. Disponível em https://www.google.com.br/maps
} 
Talvez seja esta a grande questão que este artigo não consegue esclarecer: de fato não existe uma política de divulgação e marketing da ferramenta Google Arts and Culture, o sistema de ajuda e contato do Google é direcionado para cada ferramenta e, de forma surpreendente, o Google Arts and Culture não figura na lista de ajuda on-line. Acredita-se que a ferramenta possui um grande potencial de se tornar um expoente cultural digital, pois não há como limitar sua capacidade de disponibilizar e divulgar os produtos culturais da humanidade. Portanto, ela deveria ser melhor divulgada, devendo, ainda, figurar dentro do sistema de ajuda on-line do Google.

A segunda questão levantada em relação à ferramenta como objeto que possibilita a visita virtual ao museu é o fato de "não ser mais possível separar tecnologia e cultura". É importante destacar que esta análise foi realizada em relação ao objeto e não à produção cultural. O cerne do debate foi relacionado às formas como as ferramentas de acesso e mediação estão criando uma significação virtual da representação humana, gerando uma tendência à universalidade da forma e do agir nas redes, criando uma possibilidade turística mediada.

É interessante notar como a ferramenta Google Arts and Culture despertou uma noção de pertencimento cultural através do domínio das ferramentas digitais, pois, ao final da discussão sobre a relação entre a cultura e tecnologia, o grupo concluiu que o agir na rede (navegar, acessar as redes sociais, pesquisar sobre o clima, sobre o turismo, sobre artigos acadêmicos, dentre vários outros citados) está relacionado a uma ferramenta que sobrevive nas redes.

Lançando um olhar generalista sobre a experiência com a ferramenta Google Arts and Culture, durante a visita virtual ao museu Inhotim, sendo este o primeiro contato de grande parcela do grupo com uma ferramenta que cria uma realidade virtual, verificou-se que esses dispositivos estão se enraizando nas relações culturais contemporâneas, e que a cultura digital está em um processo de consolidação. Todavia, foi a capacidade de aculturação criada pela Google através do Arts and Culture que mais chamou a atenção.

A velocidade que a maior parte do grupo apresentou em se identificar culturalmente com a ferramenta, após poucos minutos de utilização, representa um fenômeno que reflete o imediatismo das imagens digitais, sobretudo a capacidade dessas imagens (quando mediadas por uma ferramenta como o Arts and Culture) de se tornarem extensões sígnicas do corpo. O Google Arts And Culture não está apenas (re) significando o acesso aos espaços artísticos, está realizando uma aculturação universal da tecnologia como meio de acesso e de representação cultural.

\section{A VirTualizaÇÃo das Visitas aOS MUSEUS}

O conceito de virtual deste artigo parte de uma experiência das redes digitais. O virtual como simulação de uma realidade experimentada faz parte da cultura dos seres humanos desde os primeiros desenhos nas cavernas que visavam retratar uma realidade experimentada pela visão ou pelo imaginário. O digital retira a prerrogativa da experimentação para a definição de virtual, quando representado pela mão humana ou capturado por uma tela analógica, sempre representará um recorte do espaço tempo real ou 
imaginário (Canton, 1997, p. 134). Em uma dinâmica virtual, não existe este recorte de espaço tempo, o virtual digital se materializa de acordo com os comandos algorítmicos que são acionados. A pesquisa de campo mencionada neste trabalho deixou clara esta questão. Todos os participantes acessaram o Google Arts and Culture ao mesmo tempo, obtendo experiências completamente diversas de uma mesma representação virtual digital. A forma como cada participante acionou o algoritmo permitiu que a ferramenta retornasse com espaços e tempos completamente diversos.

No espaço virtual digital, o estatuto do corpo se modifica, é como se a mente se separasse do corpo para viver a experiência do virtual. Nos acessos virtuais, é possível vivenciar a experiência de se locomover por um local indefinido, tendo a sensação real de movimento, mesmo estando estático diante da tela (Leão, 1999, p. 29).

Esta é questão preponderante para se definir o virtual digital: trata-se de uma simulação algorítmica, em que o papel do usuário diante deste é imprescindível para a forma como esta simulação irá materializar-se. É a decodificação das telas tentando significar uma relação emulada que tem a intenção de tornar-se atual (em ação). Logo a virtualização é o ato de criar ambientes algorítmicos que permitem a construção de um sistema, que tende a materializar, através de imagens, um simulacro digital. Este simulacro digital abre imensas possibilidades para se pensar o turismo contemporâneo, o que leva à necessidade de trabalhar o conceito de tecnologia como uma proposta de mediação.

\section{O Google Arts and Culture como uma tecnologia cultural}

Conceituar e problematizar a tecnologia dentro deste trabalho requer abordar duas questões fundamentais: a tecnologia, como ferramenta que permite a representação técnica, imaginária e simbólica; e finalmente a tecnologia como evolução inerente à produção humana, que tem como foco a exponencialização dos sentidos. Como o objeto deste trabalho busca as representações de uma proposta turística através de imagens digitais, que podem servir como mediadoras de uma visita virtual ao museu, discutir a tecnologia sob estas óticas se torna uma questão desejável e necessária.

A experimentação e a pesquisa de campo deste trabalho partem de uma premissa tecnológica, pois a visita virtual ao museu somente pode ocorrer através de uma mediação tecnológica, em especial a que ocorre no ciberespaço do Google Arts na Culture. Esta ferramenta que permite a visualização de obras de artes em diversos museus e espaços públicos está se transformando no locus virtual onde a fruição e a contemplação podem ocorrer de forma remota.

A possibilidade de vislumbrar o conceito de aura virtual surge da observação e da interação quase orgânica entre máquina, homem e imagem. O Google Arts and Culture instrumentaliza, por meio de sua tecnologia embarcada, uma possibilidade única de se pensar o "aqui e estar da obra" de forma digital; enfim pensar o Google Arts Project é pensar uma tecnologia cultural contemporânea.

A tecnologia pode ser pensada como uma ferramenta que potencializa a técnica de se (re) produzir algo; é uma exponencialização dos sentidos que eleva a capacidade 
produtiva humana; não é mais possível pensar a produção humana sem pensar a tecnologia, desde o momento em que a humanidade descobre as pedras como extensões de suas capacidades motrizes até o advento da era digital, o desenvolvimento das sociedades humanas é reflexo dos avanços tecnológicos, desde as pedras lascadas até o advento do computadores e dispositivos tecnológicos pessoais (smartphones, tablets, óculos de realidade aumentada, etc.)

Segundo Gomez (2006, p. 191), a técnica desempenha um papel simbólico fundamental nas sociedades, e as redes são a expressão máxima de uma inversão polar que desloca a tecnologia do ambiente físico para o ambiente virtual. Acrescentaria a esta construção teórica o fato de que as redes, além de provocarem esta inversão polar, estão subvertendo a tecnologia. Nas redes, a tecnologia é o instrumento que constrói as tramas virtuais, ao mesmo tempo em que é a principal ferramenta para a criação de signos, que nascem digitais e se transferem para a memória e para o imaginário.

Barbero (2006, p. 54) apresenta a revolução tecnológica como sendo o fenômeno que introduz no cotidiano social não somente uma enorme quantidade de máquinas, mas um novo tipo de relação entre os processos simbólicos que constituem o cultural através das produções de signos tecnológicos (Facebook, Google, Android, IOS). Esta simbologia das máquinas instrumentaliza um novo modo de produzir, associado a um novo modo de comunicar que transforma o conhecimento em uma força produtiva direta.

Quando Barbero (2006) apresentou este ensaio, não era possível vislumbrar uma ferramenta de produção e consumo simbólico como o Google Arts and Culture. Ao atualizarem-se os conceitos de Barbero em relação a esta tecnologia, fica evidente que o conhecimento presente em uma ferramenta que se propõe a virtualizar boa parte do acervo artístico e cultural disponível para a humanidade está, de fato, transformando conhecimento em uma força produtiva direta. Quantos trabalhos, abstrações, teorias, ações culturais e turísticas podem ser derivadas do Google Arts and Culture? Sem dúvida, as possibilidades de produção diretas e indiretas, a partir desta tecnologia, são incomensuráveis.

O lugar da cultura está sendo deslocado quando a tecnologia passa a ser mediadora da comunicação não mais de forma instrumental, mas passa a representar uma estrutura que sustenta a produção cultural. A tecnologia contemporânea não pode mais ser remetida a aparelhos, computadores e dispositivos móveis. Ela é significante de novos modos de percepção, de linguagens, de imaginários e de escritas (Barbero, 2006, p. 54).

A tecnologia desde o advento da modernidade está deslocando os saberes para uma esfera cada vez mais pulverizada, reestruturando os estatutos cognitivos e institucionais, reduzindo as fronteiras entre razão e imaginação, saber e informação, natural e artificial, arte e ciência (Barbero, 2006, p. 54). Pensar a visita virtual ao museu materializada pelo Google Artes and Culture (nas telas), é poder apresentar uma ferramenta tácita da evolução tecnológica como um instrumento que cria uma nova forma cognitiva de poder produzir e consumir bens simbólicos.

Esta concepção aproxima a definição de tecnologia deste trabalho ao conceito de "Tecnologia da Inteligência", ao integrar as construções imagéticas humanas a uma força 
de produção cognitiva que une imaginário, hipertexto, em uma constante ressignificação simbólica, que é resultado da simbiose entre homem e suas próteses sensório-cognitivas (Moraes, 2006, p. 23). É fundamental apresentar o Google Artes and Culture como uma parcela da tecnologia digital que permite a representação técnica, imaginária e simbólica, reflexo da produção humana digital a qual possibilita a exponencialização dos sentidos.

Por mais que se possa discutir as reais e ainda significantes diferenças entre a disponibilidade física e virtual, como fechar os olhos diante de uma tecnologia que possibilita o acesso a grande parcela da cultura humana? Como não perceber este deslocamento cognitivo? Como não colocar em "xeque" fruição e contemplação em seu sentido clássico? Como não pensar em uma aura digital? O "aqui e estar" auráticos não são mais exclusividade da obra e do artista? A aura digital será uma estrutura complexa que permitirá este momento único a partir das hibridizações de todos os acervos disponíveis em uma plataforma de acesso remoto como o Google Arts and Culture?

A tecnologia das redes, alinhada aos computadores e dispositivos móveis, através de suas manipulações de símbolos, estão inaugurando uma fusão entre corpo e tecnologia. A interatividade criada pela tecnologia como instrumento contemporâneo de mediação comunicacional, ao hibridizar sons, imagens e textos está deslocando o eixo da produção humana de sensório-motor para sensório-simbólico (Barbero, p. 57). Do ponto de vista produtivo, uma visita virtual ao museu não é mais que uma experiência sensório-simbólica.

\section{VISITA VIRTUAL AO MUSEU: UMA EXPERIÊNCIA TURÍSTICA}

A tecnologia contemporânea que possibilita a visita virtual ao museu é o reflexo de um caminho evolutivo que, em seu estágio digital, está hibridizando modos e meios de produção, valores, comportamentos, linguagens, hábitos e relações sociais. A tecnologia se tornou, ao mesmo tempo, ferramenta, estrutura e meio através do qual a produção e a representação humana podem acontecer, ser produzidas, modificadas e consumidas.

A tecnologia, por meio de seu empoderamento simbólico, transporta os sentidos e o imaginário para dentro das telas. A imagem digital torna-se o principal representante simbólico da tecnologia em rede. Todos os sentidos humanos são exponencializados na tecnologia digital por meio da visualidade. Toda a legibilidade das redes se inicia no visual. A imagem digital é o estopim tecnológico para a ampliação dos sentidos nas redes. O Google Arts and Culture consegue conduzir um observador através do museu, transferindo a sensação de mobilidade, texturas e sons apenas por intermédio da visão. Através de uma tela, esta ferramenta do Google é capaz de transportar o observador de seu Facebook ao MoMa, do Louvre para seu email, passando pelo Instituto Inhotim.

Dentro desta catarse criada pela tecnologia, a representação se transformou em uma arena antropológica digital. É possível definir a visita virtual ao museu, então, em uma das expressões máximas de produção e consumo culturais-digitais, que somente podem existir e serem representadas por meio de uma tecnologia híbrida, que abarca uma diversidade de produções de conhecimento e sentidos que nascem de forma digital 
para então povoar a subjetividade, o imaginário e a memória. A mediação é o elemento que permite discutir a visita virtual ao museu como sendo uma proposta subjetiva, que une o imaginário à memória para criar uma experiência turística virtual.

Conceituar a mediação se torna fundamental para entender a dinâmica teórica deste artigo. $\mathrm{O}$ ato de mediar, em sua conceituação original, está diretamente ligado aos meios de comunicação que se tornaram um intermediário entre a informação e o receptor. Todavia, discutir a mediação em uma visita ao museu infere uma grande quantidade de sentidos, valores e ideologias que estarão sendo representados entre o interlocutor e as obras presentes no museu. Discutir o conceito de mediação tecnológica em uma visita virtual ao museu representa substituir o interlocutor por uma tecnologia, que não é neutra em seu papel mediador (Bauman, 2007, p. 179).

O conceito de mediação foi introduzido no âmbito das comunicações como propriedade exclusiva dos meios: mediation. Barbero (2006) usou o termo para significar a descentralização da comunicação das mídias, passando assim a cultura a representar a principal forma de mediação (Moraes, 2006, p. 81). Entender o jogo da mediação tecnológica requer uma premissa fundamental: deixar de conceber a mediação como sendo oriunda dos meios e que estes são de uma expressão da mediação.

A mediação, em uma dinâmica tecnológica digital, em que é possível se realizar uma visita virtual ao museu, é resultado de um processo estruturante, que vem de diversas fontes tecnológicas e sociais. O que a ferramenta Google Arts and Culture se incube de materializar são as diversas estruturas que envolvem as redes, a comunicação social do museu, o enunciado dos artistas, a estrutura lógica e física dos museus, os interesses sociais e culturais dos curadores e do próprio museu.

Remeter a mediação tecnológica a uma dinâmica representativa da globalização, ou a um reflexo do capitalismo tecnológico (tardio), não é a questão fundamental a ser discutida sob a égide deste trabalho, mas sim apresentar, definir a mediação tecnológica como um conjunto de meios que se torna possível através de uma ferramenta digital que consegue materializar todos estes meios, interesses e estratagemas sociais em uma construção imagética capaz de iluminar um acesso virtual entre uma instituição, seu acervo e o usuário. O ponto de consolidação destes três atores é uma ferramenta criada e gerenciada pelo Google, capaz de miscigenar estas tensões e criar, através de imagens digitais, o ambiente virtual onde, de fato, a mediação possa ocorrer, gerando, a partir dela, a visita ao museu.

A mediação tecnológica é capaz de criar e recriar ambientes, pois, ao unir os meios, como o vídeo, o áudio e a escrita, as telas se tornam confortáveis à experiência do contemplar e do fruir. Ao criar uma realidade simulada, o Google Arts Project consegue recriar uma situação que, até então, somente poderia ser experimentada de forma presencial. Esta mediação se difere da mediação das imagens impressas, pois a imagem digital permite a recriação do ambiente do museu e da obra, permitindo ainda que a tela se desloque como uma simulação do olhar e do caminhar.

A mediação humana em museus, segundo Stelarc (1997, p. 20), é uma provocação que instiga o outro a perceber diferentes e inusitados ângulos, criando perspectivas 
diferentes do próprio pensamento do observador, em que o mediador se coloca como uma ponte entre o observador e a obra, despertando interesses e interrogações. A mediação tecnológica está destinada a ser esta ponte, porém sua concepção é pré-formatada sem a capacidade de aguçar o interesse. Durante a pesquisa de campo, esta questão se tornou clara. Embora as possibilidades criadas pela ferramenta de acesso virtual ao museu sejam quase inesgotáveis, a falta de uma mediação humana é latente. Todavia, a mediação tecnológica cumpre o papel de ser uma ponte entre espectador e obra, mas a capacidade de estimular interesses e questionamentos se apresenta reduzida. Talvez do ponto de vista estrutural seja este o maior desafio (em termos de melhoria), para o Google Arts and Culture.

A mediação tecnológica possui algumas características importantes. A possibilidade de acesso às obras em escolas, associações, grupos de interesses, se bem explorada, permite uma maior aproximação entre arte e público. Dentro de ações educacionais, a mediação tecnológica pode criar um ambiente propício à fruição e à interpretação das artes de forma remota. Este dado torna-se interessante quando é sabido que uma grande parcela da população não possui acesso direto às artes e/ou aos museus (Virilio, 1993, p. 29).

Um bom exemplo de como a mediação tecnológica pode ser um instrumento relevante, para a aproximação entre obra e público, foi experimentado pelo projeto OI Futuro - Museu das Telecomunicações com a experiência de ferramentas e jogos disponibilizados em estações através do museu, que, sem a presença de um educador, estimulavam a fruição e a discussão sobre as obras. Aquela experiência demonstrou, para os organizadores do museu, como a tecnologia poderia ser aplicada de forma efetiva para aproximar as obras do público. O resultado destas ferramentas como mediadoras foi uma maior interação entre o público e as artes.

Santaella e Arantes (2008, p. 41) apresentam a mediação em museus como uma relação que deve estar aberta ao fortuito, onde a diversidade dos grupos e sua bagagem cultural devem ser levadas em consideração na construção desta relação. O diálogo é apresentado como uma forma elementar para o sucesso da mediação, ampliando as possibilidades e o espectro de compartilhamentos possíveis. Tais observações são fundamentais para se pensar a visita virtual ao museu, pois a mediação tecnológica não consegue abordar, no momento da visita, questões de diversidade e identidade. Durante a pesquisa de campo (visita virtual por meio do Google Arts and Culture), o grupo focal demonstrou certa inquietação com esta padronização. Todavia, não houve nenhuma inferência sobre tal fato ser um impeditivo à realização da visita.

Arantes (2008, p. 51) apresenta uma construção sobre o público na relação mediada, evidenciado o papel do enunciado em uma mediação que deve levar em consideração para quem se fala e o que se fala. Arantes (2012, p. 52) apresenta ainda a inquietação que a mediação cria entre público e mediador, pois a mediação tende a provocar, instigar, impactar e transformar a percepção e o imaginário. Esta é uma questão fundamental, pois a mediação não é neutra, a mediação deverá sempre provocar uma reação ao público e ao próprio mediador. 
Em uma relação de mediação tecnológica, a presunção de uma neutralidade do mediador deve ser refletida. A ferramenta Google Arts and Culture apresenta-se de forma interessante neste aspecto. Ela subverte a mediação subjetiva ao museu que fica responsável por todas as informações que deverão ou não constar na visita virtual. Ela se torna neutra em relação ao conteúdo, mas paradoxalmente ela não é flexível quanto a forma que a mediação irá ocorrer. Esta homogeneidade da forma evidencia que a ferramenta está cumprindo seu papel de consolidação dos meios em uma ferramenta que tende à universalidade, abstendo-se dos interesses, valores e ideologias das instituições.

Um dos principais desejos em uma relação mediada (especialmente em um museu) é a autonomia. Neste quesito convergem a mediação humana e a tecnológica, pois ambas são resultado das construções sociais e culturais de mediadores e mediados. A relação de mediação é uma realidade cada vez mais fissurada pela tecnologia. Com o advento da era digital, a tecnologia computacional está se tornando mediadora da vida social. Discutir a mediação em uma visita virtual ao museu é realizar um recorte da mediação tecnológica que está digitalizando o viver e o representar da sociedade contemporânea.

\section{VIRTUAL X PRESENCIAL: ANÁLISE DA EXPERIÊNCIA DO INSTITUTO INHOTIM}

As análises sobre as experiências virtual e presencial serão realizadas a partir da compilação discursiva apresentada pelo grupo focal, evidenciando a subjetividade contemplativa das experiências. Serão apresentadas, ainda, as percepções sobre a fruição e o consumo simbólico nestes dois momentos (virtual e presencial).

O grupo focal chegou a uma percepção sobre o uso das imagens digitais como mediadoras de uma visita ao museu: as imagens digitais por permitirem a interação, aguçaram a criatividade, permitindo o ordenamento e a significação de uma dinâmica digital para a construção de uma memória sensorial que não foi experimentada de forma presencial. Este momento se alinha com a já discutida concepção de uma aura digital. Existe um momento único das imagens digitais que edificam a memória, transcendendo a visualidade dos objetos a uma fruição que se ressignifica em uma construção cognitiva invisual.

A construção do paralelo realizado pelo grupo demonstra que a fruição digital está ligada à união sensorial. Evidenciando a bagagem cultural individual e a heterogeneidade do grupo, cada participante destacou um ou mais sentidos que puderam ser percebidos como fundamentais para a compreensão e percepção das obras digitalizadas. Porém, foi evidenciado que a experiência de visitar uma obra presencialmente, após a realização da visita virtual, cria uma relação complementar, que exponencializa a experiência da visita ao museu.

O fato de o grupo trabalhar o conceito de complementação, para maximizar a fruição da obra, corrobora com a temática já abordada de existência de uma fruição digital. O comportamento grupal destaca que, durante a visita virtual, ocorreu uma fruição. Todavia, ela não se manifesta da mesma forma durante a contemplação física. No entanto, esta não é plausível de ser descartada, considerada inválida ou até mesmo 
inexistente; é uma fruição que se manifesta de outra maneira. A experiência da galeria Garaicoa exponencializaria a análise sobre a fruição digital e ainda "abriria as portas" para a ratificação da aura digital.

Durante a análise, foram evidenciadas, de forma subjetiva, as experiências do grupo quanto às manifestações da fruição digital e da aura digital. Foi se tornando latente a partir da visita presencial que a visita virtual, além de já ter sido apontada como uma forma válida de acesso às artes, também permitia uma experiência cultural representativa. Elementos de identidade, (re)significações, construções discursivas e manifestações produtivas estiveram presentes durante a visita virtual, e estavam se manifestando na construção comparativa entre as experiências.

A capacidade das imagens digitais de significarem ambientes e paisagens ratifica a dimensão cultural imagética, em especial em sua vertente virtual, que permite a imersão e o controle através de uma mediação tecnológica. Tornar a imagem digital manipulável, seguindo o sentido da visão, permite ao imaginário assimilar a experiência virtual como vivenciada. Esta forma de significação memorativa digital possui um grande impacto na construção cultural contemporânea.

Ao criar um imaginário oriundo das imagens digitais, a produção cultural está deslocando a legitimidade imagética para a dinâmica das redes. Este poder supera a capacidade memorativa das imagens estáticas como a fotografia, e a interatividade transcende a pseudo-sensoriedade de movimento do cinema. Sob as "bênçãos" da cultura digital, as experiências virtuais se dignam a representar, através de um algoritmo, as inúmeras possibilidades que serão acionadas pelos usuários. Estes podem compor sua subjetividade dentro das ferramentas virtuais.

A cultura digital está experimentando ainda de forma incipiente o poder das imagens digitais. A experiência com o grupo focal demonstrou que as potencialidades desta união entre cultura, estética e tecnologia são profundas e performam rumo a uma matriz cultural digital. O reconhecimento e a identidade dentro das plataformas digitais estão latentes na aculturação digital experimentada pela sociedade contemporânea. $O$ fato de o grupo não negar a validade da plataforma digital ilustra essa necessidade de pertencimento digital. A cultura digital se forma majoritariamente através das imagens digitais e a virtualização potencializa o imaginário cultural através da experiência cultural (Oliveira, 2007, p. 232).

Muitas outras questões podem ser abordadas e outros vieses podem ser discutidos a partir dos dados captados durante as experiências virtuais e presenciais. Todavia, esta análise se limitou ao recorte cultural que evidencia a relação das representações artísticas com a tecnologia. O fato de a estética ser apenas pontual durante as análises realizadas é fruto deste recorte, que buscou evidenciar as tensões entre cultura e tecnologia. De fato, as possibilidades de se realizar turismo de forma virtual não podem ser desconsideradas. O recorte da visita virtual ao museu representa uma parcela ínfima do turismo tecnologicamente mediado, mas já ilumina o futuro da tecnologia como provedora da experiência de se visitar virtualmente qualquer ambiente que esteja algoritmicamente representado nas redes (Wiener, 1970, p. 107). 


\section{CONSIDERAÇÕES FINAIS: EM BUSCA DE NOVOS OLHARES NAS VISITAS VIRTUAIS}

O trabalho realizado com o grupo focal confirmaria a validade do acesso virtual ao museu como uma possibilidade turística real, e abre as possibilidades de se discutir esta validade não por razões meramente sensório-cognitivas, mas através de uma aculturação inerente às dinâmicas digitais que constroem as representações e ressignificam o status quo da cultura contemporânea. A validade da visita virtual ao museu está diretamente ligada à necessidade de pertencimento nas redes, que demandam a migração das identidades para as esferas digitais. A legibilidade da visita virtual ao museu é a mesma que ocorre nas redes sociais, onde não importa o "como", mas "o que" se representa.

A sacralidade do museu enquanto instituição de fruição e contemplação artística não se abala diante das possibilidades de acesso virtual ao seu espaço físico e ao seu acervo, o mesmo se aplica à experiência turística de forma geral. Existe um reconhecimento cristalino de complementariedade entre os acessos virtuais e presenciais. A comparação entre as três galerias demonstra que a experiência virtual prévia proporciona um maior interesse e promove um estreitamento relacional entre obra e público.

Tendo a visita virtual sido considerada uma opção legível e válida para acessar as artes, não afetando a sacralidade do museu enquanto locus de fruição, as considerações do grupo em relação à visita virtual focaram-se na ferramenta Google Arts and Culture e as possíveis formas de maximizar sua proposta de virtualização.

O percurso deste trabalho permitiu conceituar a imagem digital dentro de um estatuto digital, que maximiza suas potencialidades discursivas associadas à capacidade de poder significar o imaginário e a memória a partir de construções matemáticas. A pseudo interatividade dessas imagens busca sua legibilidade nas mediações tecnológicas. Pensar a imagem digital como instrumento de acesso ao turismo é demonstrar a capacidade simbólica da produção e consumos culturais através da virtualização.

Como todo elemento cultural, a tecnologia possui a capacidade de (re) significar as relações simbólicas. A apropriação cultural das telas apresenta-se como "um turbilhão no rio", que necessita de novos conceitos de fruição e aura, quando estas apropriações se dignam a representar as artes. Diante do experimento realizado, tornou-se latente o reconhecimento das telas como extensão das percepções sensórias, sendo inconscientemente reconhecidas como próteses sensório cognitivas, capazes de transmitir sensações e gerar memórias.

A relação híbrida entre o homem e os dispositivos evidencia ainda a capacidade de reconhecimento, produção e consumo de signos por meio da mediação tecnológica, em especial através do reconhecimento das telas como uma extensão da visão. Esta relação cultural híbrida mediada pela tecnologia não é imune à sensibilidade humana. Portanto, é possível vislumbrar uma proposta teórica de fruição digital.

A fruição digital ocorre na comunicação com a obra de arte, que, ao ser mediada por uma plataforma tecnológica digital, estabelece uma relação discursiva nova, que não pode ser descartada nem tampouco ocorre nos mesmos moldes estabelecidos em uma contemplação presencial. Esse diálogo novo e potencialmente dialético entre arte 
e espectador, por meio de uma ferramenta como o Google Arts and Culture, é o que denomino de fruição digital.

A fruição digital de uma obra de arte implica uma reflexão filosófica do momento da fruição, quando existe uma relação de autenticidade que subverte a sensoriedade para uma razão existencial única da obra, que só ocorre em sua vertente digital. Esta capacidade foi experimentada pelo grupo focal na galeria Garaicoa, onde a obra somente se manifestou como autêntica, capaz de representar seu valor de culto em sua materialização virtual. Este momento único, autêntico, que existe sem que haja uma reprodução técnica da obra original, mas que permite a percepção de um "aqui estar" virtuais reflete o conceito de aura digital. Discutir e conceituar aura digital são temas para perguntas mais aprofundadas. A latência teórica desta definição, como um olho d'água de um manancial, abastece e alimenta intelectualmente este artigo. Não poderia, portanto, deixar de ser aqui exposta.

Como em um romance de final aberto, fecundo ao imaginário e acessível às mais diversas discussões, propomos encerrar estas reflexões, abrindo-nos ao contraditório e ao anti-hegemônico. Apenas no âmbito dos Estudos Culturais, poderíamos percorrer este caminho metodológico no qual lançamos um olhar multidisciplinar para abordar turismo como uma visita virtual, cultura, artes e tecnologia, em uma relação que busca a (re) significação das representações humanas.

\section{REFERÊNCIAS}

Arantes, P. (2008). Arte e mídia: perspectivas da estética digital. São Paulo: Editora Senac.

Ascott, R. (1997). A arte no século XXI: a humanização das tecnologias. São Paulo: Editora Unesp.

Barbero, J. M. (2006). Tecnicidades, identidades, alteridades: mudanças e opacidades da comunicação no novo século. Rio de Janeiro: Editora Mauad.

Bauman, Z. (2007). Vida para consumo: transformações das pessoas em mercadorias. Rio de Janeiro: Editora Jorge Zahar.

Benjamin, W. (2012). Benjamin e obra de arte: técnica, imagem percepção. Rio de Janeiro: Editora Contraponto.

Brandão, D., Alvelos, H. \& Martins, N. D. (2012). Contributo para a discussão sobre um novo conceito de museu através da análise de diversos casos de estudo. Comunicação e Sociedade, 22, 96-108. Retirado de http://revistacomsoc.pt/index.php/comsoc/article/viewFile/1276/1218

Canton, K. (1997). Antenas da nova sensibilidade. São Paulo: Editora Bravo.

Gómez, G. O. (2006). Comunicação social e mudança tecnológica: um cenário de múltiplos desordenamentos. Rio de Janeiro: Editora Mauad.

Jameson, F. (2001). A cultura do dinheiro: ensaios sobre a globalização. Petrópolis: Editora Vozes.

Jameson, F. (1997). Pós-modernismo. A lógica cultural do capitalismo tardio. São Paulo: Editora Ática.

Leão, L. (1999). O labirinto da hipermídia. São Paulo: Editora Iluminuras. 
Moraes, D. (2006). Sociedade midiatizada. Rio de Janeiro: Editora Mauad.

Oliveira, J. C. (2007). O museu digital: uma metáfora do concreto ao digital. Comunicação e Sociedade, 12, 147-162. DOI: 10.17231/comsoc.12(2007).1101

Santaella, L. \& Arantes, P. (2008). Estéticas tecnológicas. Novos modos de sentir. São Paulo: Editora Educ.

Santaella, L. (2003). Cultura e artes do pós-humano: da cultura das mídias à cibercultura. São Paulo: Editora Paulus.

Santaella, L. \& Arantes, P. (2012). Leitura de imagens. São Paulo: Editora Melhoramentos.

Stelarc, A. (1997). Das estratégias psicologias às ciberestratégias: a protética, a robótica e a existência remota. São Paulo: Editora Unesp.

Virilio, P. (1993). A imagem virtual mental e instrumental. Rio de Janeiro: Editora 34.

Wiener, N. (1970). Cibernética. São Paulo: Editora da Universidade de São Paulo.

\section{NotA BIOGRÁFICA}

Fernando Augusto Silva Lopes é graduado em Relações Internacionais, Mestre em Estudos Culturais Contemporâneos da Universidade FUMEC (Belo Horizonte, Brasil), discente do programa doutoral em Estudos Culturais da Universidade do Minho. Tem um interesse nas mudanças em curso nas relações entre cultura e tecnologia, em especial nas manifestações semióticas em que a tecnologia tende a hibridizar-se com os objetos culturais. Dedica uma atenção especial ao que ocorre no universo da tecnologia como elemento de construção cultural. Atualmente desenvolve uma ampla pesquisa sobre a representação cultural das imagens digitais.

Morada: Rua Zenite, número 350, apartamento 304, bloco B, Caiçara - Minas Gerais - Brasil - CEP: 30720-530

Email: fernandoaugustosilvalopes@gmail.com

\section{Submetido: $28-02-2018$}

Aceite: $26-06-2018$ 